\title{
Article \\ Comparison of Treatment Modalities for Dry Eye in Primary Sjögren's Syndrome
}

\author{
Hyunmin Ahn ${ }^{1}$, Yong Woo Ji ${ }^{1}{ }^{\circledR}$, Ikhyun Jun ${ }^{1,2}$, Tae-im Kim ${ }^{1,2}$, Hyung Keun Lee ${ }^{1} \mathbb{C}$ and Kyoung Yul Seo ${ }^{1, *}$ \\ 1 Institute of Vision Research, Department of Ophthalmology, Yonsei University College of Medicine, \\ Seoul 03722, Korea; overhyun31@gmail.com (H.A.); lusita30@yuhs.ac (Y.W.J.); hadesdual@yuhs.ac (I.J.); \\ tikim@yuhs.ac (T.-i.K.); shadik@yuhs.ac (H.K.L.) \\ 2 Corneal Dystrophy Research Institute, Yonsei University College of Medicine, Seoul 03722, Korea \\ * Correspondence: seoky@yuhs.ac; Tel.: +82-2-2228-3574; Fax: +82-2-312-0541
}

check for updates

Citation: Ahn, H.; Ji, Y.W.; Jun, I.; Kim, T.-i.; Lee, H.K.; Seo, K.Y. Comparison of Treatment Modalities for Dry Eye in Primary Sjögren's

Syndrome. J. Clin. Med. 2022, 11, 463. https://doi.org/10.3390/ jcm11020463

Academic Editor: Anat Galor

Received: 23 December 2021

Accepted: 14 January 2022

Published: 17 January 2022

Publisher's Note: MDPI stays neutral with regard to jurisdictional claims in published maps and institutional affiliations.

Copyright: (C) 2022 by the authors. Licensee MDPI, Basel, Switzerland. This article is an open access article distributed under the terms and conditions of the Creative Commons Attribution (CC BY) license (https:// creativecommons.org/licenses/by/ $4.0 /)$.

\begin{abstract}
Purpose: To evaluate the effectiveness of different treatment modalities for dry eye in primary Sjögren's syndrome with their potential overlapping influences. Methods: This study included 199 patients with newly diagnosed primary Sjögren's syndrome from 2005 to 2020. Various treatment modalities for primary Sjögren's syndrome were compared. Improvement of corneal staining based on Sjögren's International Collaborative Clinical Alliance (SICCA) scores was the primary outcome. Results: The average follow-up period was $5.4 \pm 3.1$ (range, 2.0-14.1) years. Analysis of the individual treatments showed that punctal plug insertions in the lower and upper eyelids were strongly associated with improvement of SICCA scores $(\beta=2.70$ and 1.80, $p<0.001$ and $<0.001$, respectively). With ocular surface inflammation, corneal staining scores improved significantly with steroid eye drops. Prednisolone $(1 \%)$ had the strongest association with improvement of corneal staining scores $(\beta=1.48, p<0.001)$; this was based on the frequency of administration. Without ocular surface inflammation, diquafosol (3\%), carbomer gel, and lanolin ointment were effective ( $\beta=1.37,1.06$, and 1.17; $p=0.003,0.003$, and $<0.001$, respectively). Conclusions: Punctal plug insertion, primarily targeting aqueous deficiency, is the mainstay of the treatment for dry eye in primary Sjögren's syndrome even in the presence of ocular surface inflammation. Furthermore, the effectiveness of treatment modalities for dry eye in primary Sjögren's syndrome was dependent on the presence of ocular surface inflammation.
\end{abstract}

Keywords: dry eye; ocular surface inflammation; punctal plug; Sjögren's syndrome

\section{Introduction}

Sjögren's syndrome (SS) is a long-term, progressive autoimmune disease that affects the exocrine glands, including the lacrimal and salivary glands. Its symptoms include dryness of the eyes and mouth, pain, and fatigue [1]. SS is one of the most common autoimmune diseases. Its phenotypic expression varies with geolocation and ethnicity. SS affects approximately 4,000,000 Americans. Its highest incidence (43 per 100,000 people) is registered in Europe and Asia [1-3].

Regarding symptoms and signs of dry eye disease, patients with SS have a more severe clinical presentation than those with non-SS. Furthermore, not only are the level of tear inflammatory cytokines elevated, but the composition of inflammatory cytokines are different from those with non-SS [4]. While this makes the treatment of SS challenging, there are various available treatment modalities. Several studies have explored the treatment of dry eye in primary SS [5,6]; however, these are limited owing to the small sample sizes and short follow-up periods. Clinical guidelines for the management of dry eye disease in SS are based on the effects of individual treatments [7]. However, in clinical situations, SS is rarely treated using a single treatment agent.

No studies have compared and analyzed the effects of simultaneous, long-term, multiple treatments. Since the treatment mechanisms in dry eye are not mutually exclusive but 
rather interconnected [8], it is necessary to determine the effectiveness of the individual treatments with their potential overlapping influences. The purpose of this study was to evaluate the comparative effects of treatments administered concurrently for primary SS using long-term clinical data and to suggest the therapeutic edge for the treatment of primary SS in the real world.

\section{Methods}

This observational study was conducted at Severance Hospital, Yonsei University, College of Medicine, South Korea, between January 2005 and December 2020. The Severance Hospital Clinical Research Ethics Committee approved the study protocol (IRB protocol number-4-2021-0682). The study was conducted in accordance with the tenets of the Declaration of Helsinki.

\subsection{Participants}

All new patients with primary SS who were followed up for at least 2 years were enrolled in the study. Diagnosis of primary SS was based on the American-European Consensus Group 2002 definition and the revised 2016 criteria, including findings of systemic, serological, and immunological examinations $[9,10]$. Patients with concomitant autoimmune diseases or secondary SS were excluded. Patients with other ocular surface diseases that were not related to SS were excluded.

\subsection{Clinical Assessments}

The therapeutic effect of the treatments for primary SS were evaluated based on two clinical findings: corneal staining scores (CSS) with fluorescein and dry eye symptoms based on the quantitative ocular grading system in the Sjögren's International Collaborative Clinical Alliance (SICCA) registry [11,12]. Binary assessments evaluating the improvement in clinical signs and symptoms were conducted. An improvement of the CSS, shown by an improvement of the CSS grade (grade 0 ( 0 dots), grade 1 (1-5 dots), grade 2 (6-30 dots), and grade 3 (over 30 dots)) or CSS grade 0 , was considered the primary endpoint. Symptoms were evaluated on a 5-point scale measuring the extent of the influence of ocular surface discomfort on the functional impairment and quality of daily, social, or occupational life affected by ocular surface discomfort (very good (no symptoms and no concern), good (minimal symptoms but no concern), satisfactory (acceptable symptoms), poor (symptoms affecting quality of life), and very poor (symptoms that severely impair quality of life)). Improvement in the symptoms (seen as improvement in the symptom grade) and limited effect of dry eye symptoms on daily life (better than "good") were considered as secondary endpoints. Patients with an Efron conjunctival hyperemia scale score $\geq 2$ were considered as having ocular surface inflammation $[13,14]$.

All patients received a combined therapy with artificial tears, and the therapy was modulated step-by-step. Individual treatment plans were established when treatment plans were changed based on the methods or frequencies of the medications or procedures. The treatment methods and frequencies were set as independent variables in each treatment plan.

\subsection{Statistical Analysis}

A mixed-effects logistic regression model was used to compare the treatments for the primary and secondary outcomes. The statistical model was selected to control for various treatments, observation interval, and intra-subject variation. The individual treatments, baseline CSS, and presence of ocular surface inflammation were considered fixed effects, and patient factors were considered as random effects. A mixed-effects regression model must assume normal distribution and homogeneity of variance; therefore, the treatments that violated this statistical assumption were excluded from the analysis. Finally, 11 treatments (oral pilocarpine; low-dose oral steroid; tear substitutes (carbomer gel, lanoline ointment, and 3\% diquafosol); topical cyclosporine; topical steroid with 1\% 
prednisolone, $0.5 \%$ loteprednol, and $0.1 \%$ fluorometholone, ${ }^{7}$ and long-term punctal plug insertion (upper and lower)) were included.

The model was analyzed in two steps. First, the variables were divided into binary or qualitative categories as shown in Table 1, and the significant parameters were then subjected to the second step. Second, the variables were converted into quantitative values as dose or frequency as shown in Supplementary materials Table S1. A stratified analysis for ocular surface inflammation was performed. $p$-Values of $<0.05$ were considered statistically significant. All estimated coefficients $(\exp (\mathrm{B})$ or $\beta)$ and $95 \%$ confidence intervals $(\mathrm{CI})$ were calculated.

Table 1. The baseline demographics and the study characteristics.

\begin{tabular}{lc}
\hline \multicolumn{1}{c}{ Characteristic } & $(\boldsymbol{n}=\mathbf{1 9 1 )}$ \\
\hline Age (years, mean $\pm \mathrm{SD})$ & $52.3 \pm 12.2$ (range 35 to 90) \\
\hline Sex (Female, $\%)$ & $95.4 \pm 3.1$ (range 2.0 to 14.1) \\
\hline Observation period (years, mean \pm SD) & $\begin{array}{c}17.8, \text { of entire observational period } \\
(29.1, \text { of treatment plans) }\end{array}$ \\
\hline Ocular Surface Inflammation period $(\%)$ & 20.1 \\
\hline Corneal Staining Score * $(\%)$ & 46.0 \\
\hline Grade 1 & 33.9 \\
\hline Grade 2 & 18.5 \\
\hline Grade 3 & 53.8 \\
\hline The Symptom Scale $(\%)$ & 27.7 \\
\hline Satisfactory & \\
\hline Poor & \\
\hline Very poor & \\
\hline based on the quantitative ocular grading system by the Sjögren's International Collaborative Clinical Al-
\end{tabular}

\section{Results}

In total, 256 patients were screened. Eighteen patients were excluded owing to secondary or concomitant autoimmune diseases, rheumatoid arthritis, systemic lupus erythematosus, or IgG4-related disease. Patients with glaucoma $(n=5)$, patients with a follow-up period of less than two years $(n=5)$, patients who were enrolled in other studies $(n=3)$, and patients with disorders that affected eyelid function $(n=2$; facial palsy and hemifacial spasm) were also excluded. Patients whose baseline CSS was grade 0 or whose baseline symptom degree was better than "good" were excluded $(n=24)$. One hundred and twenty-four treatment plans (3.45\% of total treatment plans) were excluded based on the assumptions of the mixed-effects model. Finally, 199 patients with primary SS and 3468 treatment plans were evaluated.

The baseline demographics and characteristics are shown in Table 1. The average observation period was $5.4 \pm 3.1$ years (range, $2.0-14.1$ years), $95 \%$ of participants were female, and the mean age was $52.3 \pm 12.2$ years. Throughout the entire observational period, $17.8 \%$ of patients $(29.1 \%$ of treatment plans) were in the ocular surface inflammatory phase. For the baseline CSS, $20.1 \%$ of the eyes scored grade $1,46.0 \%$ grade 2 , and $33.9 \%$ grade 3 . CSS and ocular surface inflammation significantly affected the primary outcome $(p<0.001$ and 0.005 , respectively). The higher the CSS, the lower the improvement of CSS (grade $1 \mathrm{vs.}$ grade $2, \beta=0.61$ ( $95 \%$ CI, 0.49 to 0.76 ), $p<0.001$; grade 1 vs. grade $3, \beta=0.51$ ( $95 \% \mathrm{CI}, 0.39$ to 0.66$), p<0.001)$. CSS did not improve as much when ocular surface inflammation was present $(\beta=0.88$ ( $95 \%$ CI, 0.84 to 0.92$)$ ).

The therapeutic effects of the individual treatments for improvement of CSS, following adjustment for baseline CSS and ocular surface inflammation, are presented in Table 2 
and Figure 1a. Punctal plug insertions in the lower and upper eyelids were significantly effective $(p<0.001$ and $<0.001$, respectively). Carbomer gel, lanoline ointment, diquafosol, and steroid eye drops ( $1 \%$ prednisolone, $0.5 \%$ loteprednol, and $0.1 \%$ fluorometholone) were significantly effective $(p=0.037,0.033,0.005,0.009,0.042$, and 0.035 , respectively).

Table 2. Therapeutic effects of the treatments for improvement of corneal staining score (SICCA).

\begin{tabular}{|c|c|c|c|c|}
\hline \multirow[b]{2}{*}{ Treatments } & \multicolumn{4}{|c|}{$95 \% \mathrm{CI}$} \\
\hline & B & Lower & Upper & $p$ \\
\hline Oral pilocarpine & 1.017 & 0.995 & 1.039 & 0.141 \\
\hline Low-dose oral steroid & 1.220 & 0.724 & 2.057 & 0.455 \\
\hline \multicolumn{5}{|l|}{ Tear substitutes } \\
\hline Carbomer gel & 1.035 & 1.002 & 1.069 & $0.037 *$ \\
\hline Lanoline ointment & 1.142 & 1.008 & 1.274 & $0.033 *$ \\
\hline Diquafosol 3\% & 1.203 & 1.060 & 1.475 & $0.005^{*}$ \\
\hline Topical cyclosporine & 1.082 & 0.980 & 1.191 & 0.099 \\
\hline \multicolumn{5}{|c|}{ Steroid eye drops (frequency dependent) } \\
\hline Prednisolone 1\% & 1.255 & 1.058 & 1.487 & $0.009 *$ \\
\hline Loteprednol $0.5 \%$ & 1.229 & 1.002 & 1.486 & $0.042 *$ \\
\hline Fluorometholone $0.1 \%$ & 1.188 & 1.012 & 1.395 & $0.035 *$ \\
\hline \multicolumn{5}{|l|}{ Punctal plug insertion } \\
\hline Lower eyelid & 2.697 & 2.161 & 3.365 & $<0.001 *$ \\
\hline Upper eyelid & 1.801 & 1.369 & 2.370 & $<0.001$ * \\
\hline
\end{tabular}

Adjustment for corneal staining score and ocular surface inflammation. ${ }^{*} p<0.05$.

The therapeutic effects of individual treatments for symptom improvement are presented in Table 3. Punctal plug insertion in the lower and upper eyelids improved symptoms significantly $(p<0.001$ and $<0.001$, respectively). Lanoline lubricating ointment, $3 \%$ diquafosol, and all steroid eye drops ( $1 \%$ prednisolone, $0.5 \%$ loteprednol, and $0.1 \%$ fluorometholone) were significantly effective ( $p=0.023,0.022,<0.001,0.017$, and $<0.001$, respectively).

Table 3. Therapeutic effects of the treatments for improvement of symptoms.

\begin{tabular}{|c|c|c|c|c|}
\hline \multirow[b]{2}{*}{ Treatments } & \multicolumn{4}{|c|}{$95 \% \mathrm{CI}$} \\
\hline & B & Lower & Upper & $p$ \\
\hline Oral pilocarpine & 0.987 & 0.962 & 1.013 & 0.987 \\
\hline Low-dose oral steroid & 0.972 & 0.882 & 1.070 & 0.972 \\
\hline \multicolumn{5}{|l|}{ Tear substitutes } \\
\hline Carbomer gel & 1.030 & 0.996 & 1.065 & 0.089 \\
\hline Lanoline ointment & 1.040 & 1.006 & 1.077 & $0.023 *$ \\
\hline Diquafosol 3\% & 1.027 & 1.003 & 1.052 & $0.022 *$ \\
\hline Topical cyclosporine & 0.920 & 0.836 & 1.013 & 0.136 \\
\hline \multicolumn{5}{|c|}{ Steroid eye drops (frequency dependent) } \\
\hline Prednisolone 1\% & 1.297 & 1.174 & 1.434 & $<0.001 *$ \\
\hline Loteprednol 0.5\% & 1.228 & 1.034 & 1.542 & $0.017 *$ \\
\hline Fluorometholone $0.1 \%$ & 1.228 & 1.124 & 1.343 & $<0.001 *$ \\
\hline \multicolumn{5}{|l|}{ Punctal plug insertion } \\
\hline Lower eyelid & 2.867 & 2.248 & 3.655 & $<0.001 *$ \\
\hline Upper eyelid & 2.102 & 1.535 & 2.877 & $<0.001 *$ \\
\hline
\end{tabular}

Adjustment for corneal staining score and ocular surface inflammation. ${ }^{*} p<0.05$. 

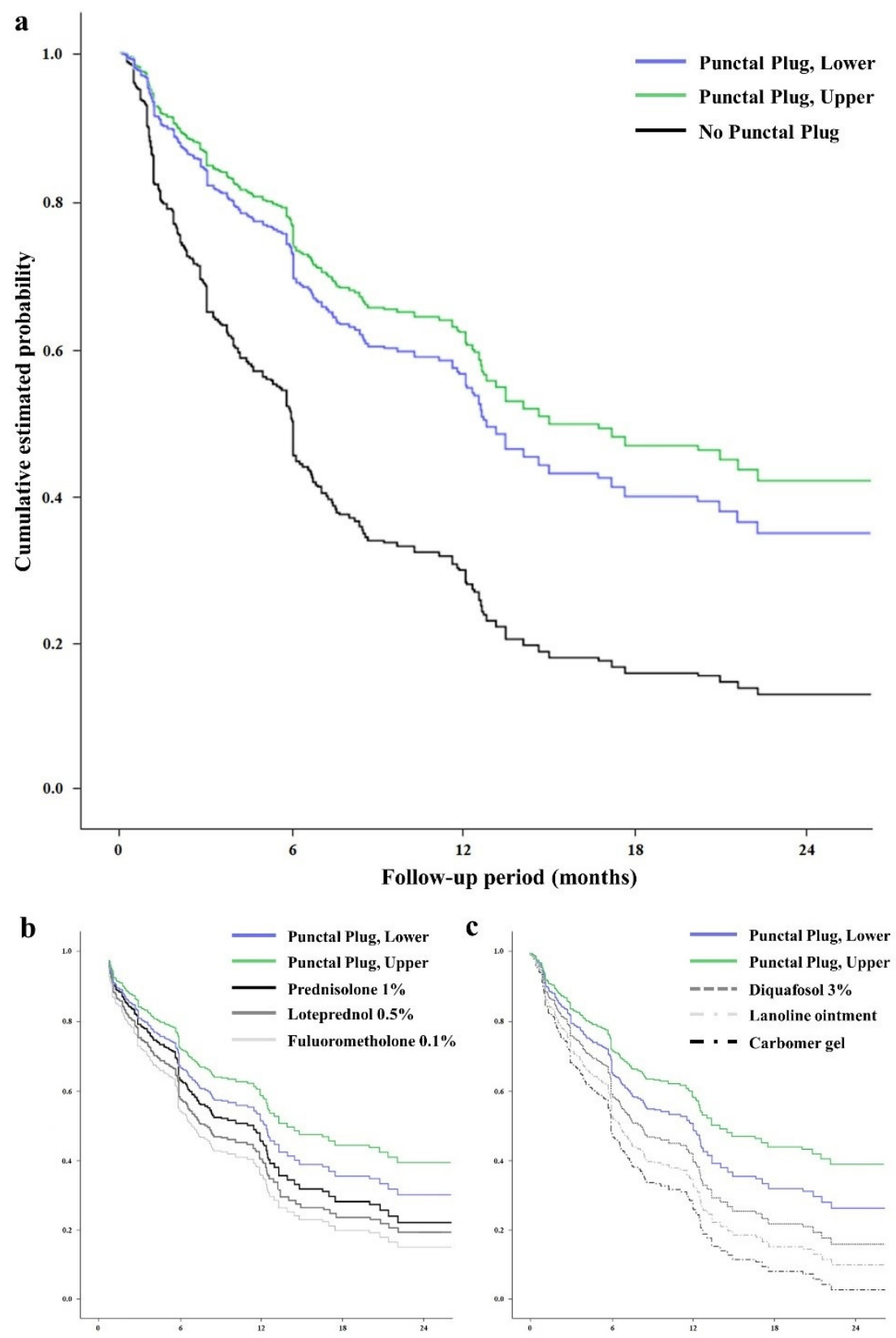

Figure 1. The (relative) cumulative estimated probability of the individual treatments for on corneal staining score in primary Sjögren's syndrome. The graphs represent the relative value according to the follow-up to the initial value. The effects of punctal plug insertion for both the lower and upper eyelid in overall data (a). The effects of the individual treatments for on the disease improvement with (b) or without (c) ocular surface inflammation.

With ocular surface inflammation (Table 4 and Figure $1 \mathrm{~b}$ ), punctal plug insertions in the lower and upper eyelids were significantly effective $(B=2.26$ and $1.70, p<0.001$ and 0.002 , respectively). Steroid eye drops and punctal plug insertions were effective. The effects of the steroid eye drops depended on the frequency of daily use, ranging from 1 to 4 times per day. Prednisolone ( $1 \%)$ was the most effective steroid eye drop ( $\beta=1.48$, $p<0.001)$, followed by $0.5 \%$ loteprednol $(\beta=1.39, p=0.012)$ and $0.1 \%$ fluorometholone $(\beta=1.25, p<0.001)$. 
Table 4. Therapeutic effects of the treatments for improvement of primary Sjögren syndrome with ocular surface inflammation.

\begin{tabular}{lcccc}
\hline \multicolumn{1}{c}{ Treatments } & \multicolumn{4}{c}{ 95\% CI } \\
\hline Oral pilocarpine & $\boldsymbol{B}$ & Lower & Upper & $p$ \\
\hline Low-dose oral steroid & 1.050 & 1.000 & 1.102 & 0.092 \\
\hline Tear substitutes & 1.250 & 0.875 & 1.745 & 0.278 \\
\hline Carbomer gel & & & & \\
\hline Lanoline ointment & 0.986 & 0.888 & 1.094 & 0.786 \\
\hline Diquafosol 3\% & 1.097 & 0.948 & 1.269 & 0.214 \\
\hline Topical cyclosporine & 1.012 & 0.924 & 1.108 & 0.800 \\
\hline Steroid eye drops (frequency dependent) & 1.084 & 0.980 & 1.199 & 0.098 \\
\hline Prednisolone 1\% & & & & \\
\hline Loteprednol 0.5\% & 1.477 & 1.292 & 1.688 & $<0.001{ }^{*}$ \\
\hline Fluorometholone 0.1\% & 1.390 & 1.076 & 1.798 & $0.012 *$ \\
\hline Punctal plug insertion & 1.245 & 1.149 & 1.350 & $<0.001{ }^{*}$ \\
\hline Lower eyelid & & & & \\
\hline Upper eyelid & 2.257 & 1.927 & 2.643 & $<0.001{ }^{*}$ \\
\hline Adust & 1.702 & 1.402 & 2.067 & $0.002 *$ \\
\hline
\end{tabular}

Adjustment for corneal staining score. ${ }^{*} p<0.05$.

Without ocular surface inflammation (Table 5 and Figure 1c), punctal plug insertions in the lower and upper eyelids were significantly effective $(\beta=2.97$ and $1.85, p<0.001$ and $<0.001$, respectively). Carbomer gel, lanoline ointment, and $3 \%$ diquafosol were significantly effective ( $\beta=1.06,1.17$, and $1.37 ; p=0.003,<0.001$, and 0.003 , respectively).

Table 5. Therapeutic effects of the treatments for improvement of primary Sjögren syndrome without ocular surface inflammation.

\begin{tabular}{lcccc}
\hline \multicolumn{1}{c}{ Treatments } & \multicolumn{5}{c}{$95 \%$ CI } \\
\hline Oral pilocarpine & Lower & Upper & $p$ \\
\hline Low-dose oral steroid & 0.991 & 0.962 & 1.022 & 0.578 \\
\hline Tear substitutes & 0.992 & 0.901 & 1.091 & 0.862 \\
\hline Carbomer gel & & & \\
\hline Lanoline ointment & 1.060 & 1.019 & 1.102 & $0.003^{*}$ \\
\hline Diquafosol 3\% & 1.171 & 1.134 & 1.211 & $<0.001^{*}$ \\
\hline Topical cyclosporine & 1.372 & 1.116 & 1.685 & $0.003^{*}$ \\
\hline Punctal plug insertion & 0.861 & 0.686 & 1.080 & 0.196 \\
\hline Lower eyelid & & & 3.897 & $<0.001{ }^{*}$ \\
\hline Upper eyelid & 2.967 & 2.259 & 2.598 & $<0.001 *$ \\
\hline Adjustment for corneal staining & 1.848 & 1.315 & &
\end{tabular}

Adjustment for corneal staining score. ${ }^{*} p<0.05$.

To show the long-term treatment modalities, we evaluated the proportions of maintenance treatments used without disease deterioration (Figure 2). Long-term punctal plug insertion was used in $80 \%$ of patients. Oral pilocarpine was used in $14 \%$ and oral low-dose steroid in $6 \%$ of the patients. Gel- and ointment-forming tear substitutes were used in $21 \%$. Diquafosol (3\%) was used in $33 \%$ of the patients. 


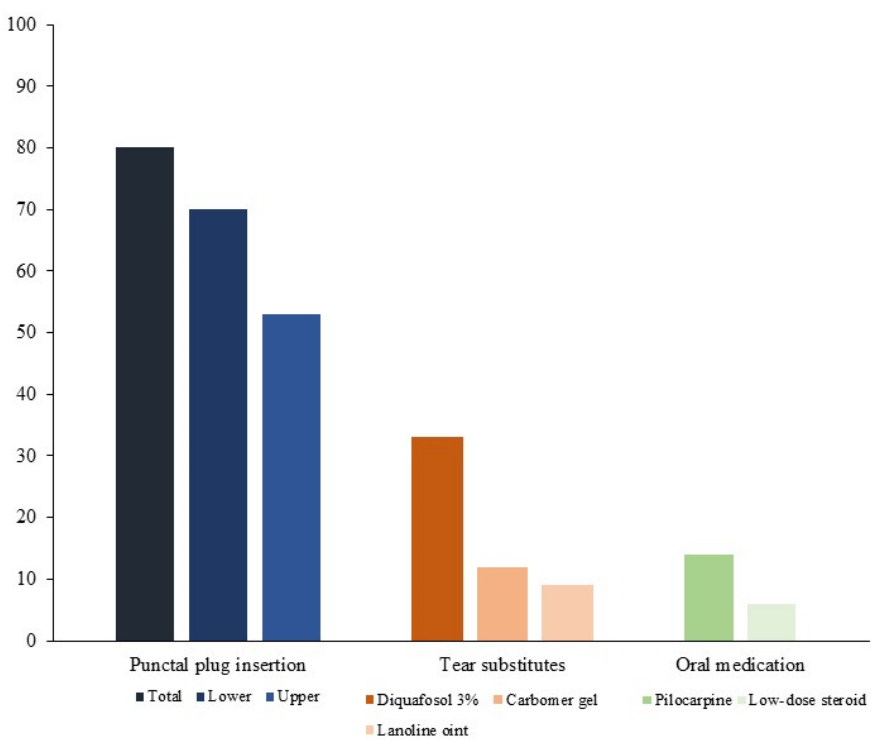

Figure 2. The proportions of the maintenance treatments for non-inflammatory period of primary Sjögren syndrome.

\section{Discussion}

Previous studies determined that various treatment modalities were effective for SS [5,6], but the results of the studies were focused on single treatment agents. Multiple treatments were administered in no study, and the treatment modality to be prioritized in actual clinical practice is still unclear. This study involved multiple treatment modalities with simultaneous interactions; the effectiveness of punctal plug insertions, especially in the inferior lacrimal punctum, which play a significant role in tear drainage and result in retention of the aqueous component of the tear film [15], was the most prominent. SS is an autoimmune disease that causes dry eyes due to lack of the aqueous component of the tear film. Our study showed that treatment for aqueous deficiency, which is the key etiology of the disease, is more important than other treatment modalities and that tear retention can reduce the frictional force that caused mechanical trauma and consequent inflammation $[8,16]$.

Multiple studies have shown the clinical effect of topical steroids on CSS $[17,18]$. However, no study clearly analyzed the effect according to potency and frequency of steroid eye drops. In our study, $1 \%$ prednisolone, $0.5 \%$ loteprednol, and $0.1 \%$ fluorometholone were effective, but this depended on the frequency of administration and presence of ocular surface inflammation. Additionally, we observed that in primary SS, the higher the potency of the steroid medication, the higher the treatment efficacy $[19,20]$. This result confirmed once again that primary SS is an inflammatory disease and showed that a treatment modality that targets inflammation, depending on its potency and frequency, is important to control the disease.

Among the tear substitutes, $3 \%$ diquafosol was superior to the other tear substitutes in patients without inflammation although gels and ointments are known to help with water, lipid, and mucin retention [21,22]. Diquafosol, an agonist of the $\mathrm{P}_{2} \mathrm{Y}_{2}$ purinergic receptor, promotes mucin secretion and membrane-associated mucin expression on the ocular surface [23-25], thus maintaining the aqueous component of the tear film and improving dry eye symptoms and signs [26].

Our study was designed to analyze the comparative effects of treatments for primary SS and does not reflect the absolute effect of individual treatments. This could be a limitation to our study. Modulating or interpreting statistical modeling outputs is difficult in a multivariate analysis [27]. For the modeling process, the dependent variables were simplified to a binary classification. A step-by-step approach for the independent, qualitative, and quantitative variables was used. However, the aim of this study was to identify which 
treatment should be prioritized and to know whether inflammation significantly affects treatment efficacy in clinical practice; the simplified results provide a clear clinical approach.

\section{Conclusions}

Punctal plug insertion, which primarily targets aqueous deficiency, is the mainstay of the treatment for dry eyes in primary SS, even in the presence of ocular surface inflammation. Punctal plug insertion can be recommended for use in combined treatments for dry eyes in primary SS. Because the long-term effectiveness of treatments for dry eyes in primary SS was dependent on the presence of ocular surface inflammation, short-term use of steroid eye drops can be considered in the presence of inflammation, and a topical mucin secretagogue can be helpful in the absence of inflammation.

Supplementary Materials: The following supporting information can be downloaded at: https:/ / www.mdpi.com/article/10.3390/jcm11020463/s1, Table S1: The independent variables of treatment modalities in this study.

Author Contributions: Conceptualization, K.Y.S.; methodology, H.A.; validation, Y.W.J., I.J., T.-i.K., H.K.L. and K.Y.S.; formal analysis, H.A.; investigation, H.A.; resources, I.J., T.-i.K. and K.Y.S.; writingoriginal draft preparation, H.A.; writing-review and editing, K.Y.S.; visualization, H.A.; supervision, K.Y.S. All authors have read and agreed to the published version of the manuscript.

Funding: This research was funded by the Korea Mouse Phenotyping Project [NRF-2013M3A9D5072551] ) from the Ministry of Science and ICT through the National Research Foundation. And the APC was funded by Yonsei University, College of Medicine and the National Research Foundation.

Institutional Review Board Statement: The study was conducted in accordance with the Declaration of Helsinki, and approved by The Severance Hospital Clinical Research Ethics Committee approved the study protocol (IRB protocol number-4-2021-0682).

Informed Consent Statement: Informed consent was obtained from all subjects involved in the study.

Acknowledgments: All named authors meet the International Committee of Medical Journal Editors (ICMJE) criteria for authorship for this article, take responsibility for the integrity of the work as a whole, and have given their approval for this version to be published.

Conflicts of Interest: The authors have no commercial or proprietary interest in any concept or product described in this article. The funding sources had no role in study design; data collection, analysis, and interpretation; manuscript writing; or the decision to submit the manuscript for publication.

\section{References}

1. Qin, B.; Wang, J.; Yang, Z.; Yang, M.; Ma, N.; Huang, F.; Zhong, R. Epidemiology of primary Sjögren's syndrome: A systematic review and meta-analysis. Ann. Rheum. Dis. 2015, 74, 1983-1989. [CrossRef]

2. Helmick, C.G.; Felson, D.T.; Lawrence, R.C.; Gabriel, S.; Hirsch, R.; Kwoh, C.K.; Liang, M.H.; Kremers, H.M.; Mayes, M.D.; Merkel, P.A.; et al. Estimates of the prevalence of arthritis and other rheumatic conditions in the United States: Part I. Arthritis Rheum. 2008, 58, 15-25. [CrossRef]

3. Brito-Zerón, P.; Acar-Denizli, N.; Zeher, M.; Rasmussen, A.; Seror, R.; Theander, E.; Li, X.; Baldini, C.; Gottenberg, J.; Danda, D.; et al. Influence of geolocation and ethnicity on the phenotypic expression of primary Sjögren's syndrome at diagnosis in 8310 patients: A cross-sectional study from the Big Data Sjögren Project Consortium. Ann. Rheum. Dis. 2017, 76, 1042-1050. [CrossRef] [PubMed]

4. Lee, S.Y.; Han, S.J.; Nam, S.M.; Yoon, S.; Ahn, J.M.; Kim, T.-I.; Kim, E.K.; Seo, K.Y. Analysis of Tear Cytokines and Clinical Correlations in Sjögren Syndrome Dry Eye Patients and Non-Sjögren Syndrome Dry Eye Patients. Am. J. Ophthalmol. 2013, 156, 247-253.e1. [CrossRef]

5. Brito-Zerón, P.; Retamozo, S.; Kostov, B.; Baldini, C.; Bootsma, H.; De Vita, S.; Dörner, T.; Gottenberg, J.-E.; Kruize, A.A.; Mandl, T.; et al. Efficacy and safety of topical and systemic medications: A systematic literature review informing the EULAR recommendations for the management of Sjögren's syndrome. RMD Open 2019, 5, e001064. [CrossRef] [PubMed]

6. Shih, K.C.; Lun, C.N.; Jhanji, V.; Thong, B.Y.-H.; Tong, L. Systematic review of randomized controlled trials in the treatment of dry eye disease in Sjogren syndrome. J. Inflamm. 2017, 14, 26. [CrossRef]

7. Foulks, G.N.; Forstot, S.L.; Donshik, P.C.; Forstot, J.Z.; Goldstein, M.H.; Lemp, M.A.; Nelson, J.D.; Nichols, K.K.; Pflugfelder, S.C.; Tanzer, J.M.; et al. Clinical Guidelines for Management of Dry Eye Associated with Sjögren Disease. Ocul. Surf. 2015, 13, 118-132. [CrossRef] 
8. Kawashima, M.; The DECS-J Study Group; Yamada, M.; Suwaki, K.; Shigeyasu, C.; Uchino, M.; Hiratsuka, Y.; Yokoi, N.; Tsubota, K. A Clinic-based Survey of Clinical Characteristics and Practice Pattern of Dry Eye in Japan. Adv. Ther. 2017, 34, 732-743. [CrossRef] [PubMed]

9. Vitali, C. Classification criteria for Sjogren's syndrome. Ann. Rheum. Dis. 2003, 62, 94-95. [CrossRef]

10. Vitali, C.; Del Papa, N. Classification criteria for Sjögren's syndrome. In Sjögren's Syndrome; Elsevier Inc.: Amsterdam, The Netherlands, 2016; pp. 47-60. [CrossRef]

11. Bron, A.J.; Evans, V.E.; Smith, J.A. Grading of Corneal and Conjunctival Staining in the Context of Other Dry Eye Tests. Cornea 2003, 22, 640-650. [CrossRef] [PubMed]

12. Whitcher, J.P.; Shiboski, C.H.; Shiboski, S.C.; Heidenreich, A.M.; Kitagawa, K.; Zhang, S.; Hamann, S.; Larkin, G.; McNamara, N.A.; Greenspan, J.S.; et al. A simplified quantitative method for assessing keratoconjunctivitis sicca from the Sjögren's Syndrome International Registry. Am. J. Ophthalmol. 2010, 149, 405-415. [CrossRef]

13. Efron, N.; Morgan, P.B.; Katsara, S.S. Validation of grading scales for contact lens complications. Ophthalmic Physiol. Opt. 2001, 21, 17-29.

14. Ferrari, G.; Rabiolo, A.; Bignami, F.; Sizzano, F.; Palini, A.; Villa, C.; Rama, P. Quantifying Ocular Surface Inflammation and Correlating It with Inflammatory Cell Infiltration In Vivo: A Novel Method. Investig. Opthalmol. Vis. Sci. 2015, 56, 7067-7075. [CrossRef]

15. Beigi, B.; Gupta, D.; Luo, Y.H.L.; Saldana, M.; Georgalas, I.; Kalantzis, G.; El-Hindy, N. Punctal function in lacrimal drainage: The 'pipette sign' and functional ectropion. Clin. Exp. Optom. 2015, 98, 366-369. [CrossRef]

16. Vu, C.H.V.; Kawashima, M.; Yamada, M.; Suwaki, K.; Uchino, M.; Shigeyasu, C.; Hiratsuka, Y.; Yokoi, N.; Tsubota, K. Influence of Meibomian Gland Dysfunction and Friction-Related Disease on the Severity of Dry Eye. Ophthalmology 2018, 125, 1181-1188. [CrossRef] [PubMed]

17. Marsh, P.; Pflugfelder, S.C. Topical nonpreserved methylprednisolone therapy for keratoconjunctivitis sicca in Sjögren syndrome. Ophthalmology 1999, 106, 811-816. [CrossRef]

18. Pflugfelder, S.C.; Maskin, S.L.; Anderson, B.; Chodosh, J.; Holland, E.J.; de Paiva, C.; Bartels, S.P.; Micuda, T.; Proskin, H.M.; Vogel, R. A randomized, double-masked, placebo-controlled, multicenter comparison of loteprednol etabonate ophthalmic suspension, $0.5 \%$, and placebo for treatment of keratoconjunctivitis sicca in patients with delayed tear clearance. Am. J. Ophthalmol. 2004, 138, 444-457. [CrossRef] [PubMed]

19. Sendrowski, D.P. Anti-Inflammatory Drugs. In Clinical Ocular Pharmacology, 5th ed.; Butterworth-Heinemann: Oxford, UK, 2008.

20. Samudre, S.S.; Lattanzio, F.A., Jr.; Williams, P.B.; Sheppard, J.D., Jr. Comparison of topical steroids for acute anterior uveitis. J. Ocular Pharm. Ther. 2004, 20, 533-547. [CrossRef] [PubMed]

21. Slaughter, B.V.; Khurshid, S.S.; Fisher, O.Z.; Khademhosseini, A.; Peppas, N.A. Hydrogels in Regenerative Medicine. Adv. Mater 2009, 21, 3307-3329. [CrossRef]

22. Koroloff, N.; Boots, R.; Lipman, J.; Thomas, P.; Rickard, C.; Coyer, F. A randomised controlled study of the efficacy of hypromellose and Lacri-Lube combination versus polyethylene/Cling wrap to prevent corneal epithelial breakdown in the semiconscious intensive care patient. Intensive Care Med. 2004, 30, 1122-1126. [CrossRef]

23. Fujihara, T.; Murakami, T.; Nagano, T.; Nakamura, M.; Nakata, K. INS365 Suppresses Loss of Corneal Epithelial Integrity by Secretion of Mucin-like Glycoprotein in a Rabbit Short-term Dry Eye Model. J. Ocul. Pharmacol. Ther. 2002, 18, 363-370. [CrossRef] [PubMed]

24. Takaoka-Shichijo, Y.; Sakamoto, A.; Nakamura, M. Effect of diquafosol tetrasodium on MUC5AC secretion by rabbit conjunctival tissues. Atarashii Ganka (J. Eye) 2011, 28, 261-265.

25. Takaoka-Shichijo, Y.; Nakamura, M. Stimulatory effect of diquafosol tetrasodium on the expression of membrane-binding mucin genes in cultured human corneal epithelial cells. J. Eye 2011, 28, 425-429.

26. Takamura, E.; Tsubota, K.; Watanabe, H.; Ohashi, Y. The Diquafosol Ophthalmic Solution Phase 3 Study Group A randomised, double-masked comparison study of diquafosol versus sodium hyaluronate ophthalmic solutions in dry eye patients. Br. J. Ophthalmol. 2012, 96, 1310-1315. [CrossRef] [PubMed]

27. Soong, S.J.; Balch, C.M. Multivariate analysis. JAMA 1983, 250, 2471-2472. [CrossRef] 